\title{
The emerging roles of phosphatases in Hedgehog pathway
}

\author{
Long Zhao ${ }^{1}$, Liguo Wang ${ }^{2}$, Chunli Chi ${ }^{2}$, Wenwen Lan $^{2}$ and Ying Su ${ }^{2^{*}}$ (D)
}

\begin{abstract}
Hedgehog signaling is evolutionarily conserved and plays a pivotal role in cell fate determination, embryonic development, and tissue renewal. As aberrant Hedgehog signaling is tightly associated with a broad range of human diseases, its activities must be precisely controlled. It has been known that several core components of Hedgehog pathway undergo reversible phosphorylations mediated by protein kinases and phosphatases, which acts as an effective regulatory mechanism to modulate Hedgehog signal activities. In contrast to kinases that have been extensively studied in these phosphorylation events, phosphatases were thought to function in an unspecific manner, thus obtained much less emphasis in the past. However, in recent years, increasing evidence has implicated that phosphatases play crucial and specific roles in the context of developmental signaling, including Hedgehog signaling. In this review, we present a summary of current progress on phosphatase studies in Hedgehog pathway, emphasizing the multiple employments of protein serine/threonine phosphatases during the transduction of morphogenic Hedgehog signal in both Drosophila and vertebrate systems, all of which provide insights into the importance of phosphatases in the specific regulation of Hedgehog signaling.
\end{abstract}

Keywords: Hedgehog pathway, Phosphorylation, Phosphatase, Kinase

\section{Background}

The Hedgehog $(\mathrm{Hh})$ pathway is a conservative liganddependent cellular signaling mechanism, playing a vital role in diverse biological processes, such as cell proliferation and differentiation, embryonic development, and maintenance of stem cell status in adults [1]. Aberrant Hh signaling activities have been implicated in many human disorders including birth defects and cancers $[2,3]$. Therefore, the activity of Hh signaling is required to be precisely controlled.

Protein phosphorylation is one of the most important and well-studied post-translational modifications [4]. Nearly one-third of proteins in cells are subject to at least one-time phosphorylation during their whole lives [5]. Protein phosphorylation is a reversible process, mediated by two types of enzymes: protein kinase and protein phosphatase [6]. A protein kinase is responsible for transferring a phosphate group from ATP to a serine, threonine or tyrosine residue at a substrate protein, while a phosphatase is in charge of removing phosphates from the substrate. The balance between kinase and

\footnotetext{
* Correspondence: suying@ouc.edu.cn

${ }^{2}$ Institute of Evolution \& Marine Biodiversity, College of Marine Life Sciences,

Ocean University of China, Qingdao 266003, China

Full list of author information is available at the end of the article
}

phosphatase activities controls phosphorylation status of a substrate protein, alteration of which is capable of affecting its almost every aspect, such as conformation/structure, stability, activity, protein-protein interaction [6]. In contrast to protein kinases, protein phosphatases have been much less studied. They were initially considered as possessing broad and constitutive activities without functional specificities. However, increasing evidence is indicating that protein phosphatases are regulated in complex manners and are highly specific towards different protein substrates [6].

In the context of developmental signal transduction, protein phosphorylation has been revealed to play a critical role in precisely controlling the status and amplitude of signaling pathways [6]. In Hh signaling pathway, several core components have been found to undergo phosphorylations, which significantly contribute to proper controls of Hh signaling outcomes [7]. Although the executing kinases in these phosphorylation events have been intensely studied [8], relatively little is known about the responsible protein phosphatases. In this review, we mainly summarize emerging studies of phosphatases involved in regulation of $\mathrm{Hh}$ signaling in recent years, with a highlight of multiple employments of protein phosphatase $2 \mathrm{~A}(\mathrm{PP} 2 \mathrm{~A})$, one 
of abundant and important cellular protein phosphatases, during Hh signal transduction cascade, emphasizing the equal importance of phosphatase as kinase in regulating Hh signaling.

\section{Principles of Hh signaling transduction}

Since the original discovery of hh gene in Drosophila melanogaster as a regulator of body patterning during embryonic development, the knowledge about principle mechanism of Hh signal transduction has dramatically increased over the past decades [1, 9]. The intense genetic research in Drosophila has elucidated the core Hh signal transduction cascade (Fig. 1 a and b), which is initiated by two transmembrane proteins, a signal receptor Patched (Ptc) and an essential signal activator Smoothened (Smo). In the absence of Hh ligand, Ptc inhibits Smo activity, probably by preventing its cell surface localization. A transcription factor Cubitus interruptus $(\mathrm{Ci})$ is proteolytically processed, which is facilitated by a cytoplasmic signal transducer complex consisting of Costal2 (Cos2), Fused (Fu), and Suppressor of Fused (Sufu), to produce a transcriptional repressor CiR for Hh target genes (Fig. 1a). Once Hh binds to Ptc, Smo is relieved from Ptc inhibition and becomes activated, eventually resulting in the stabilization of $\mathrm{Ci}$, which is converted to a transcriptional activator $\mathrm{CiA}$ to replace $\mathrm{CiR}$ in nucleus and switch on the transcription of Hh target genes (Fig. 1b) [10-17].

The core Hh signal transduction shares same principle from Drosophila to mammals, although the mammalian pathway is more complex owing to the presence of multiple ligands, receptors and transcription factors (Table 1)
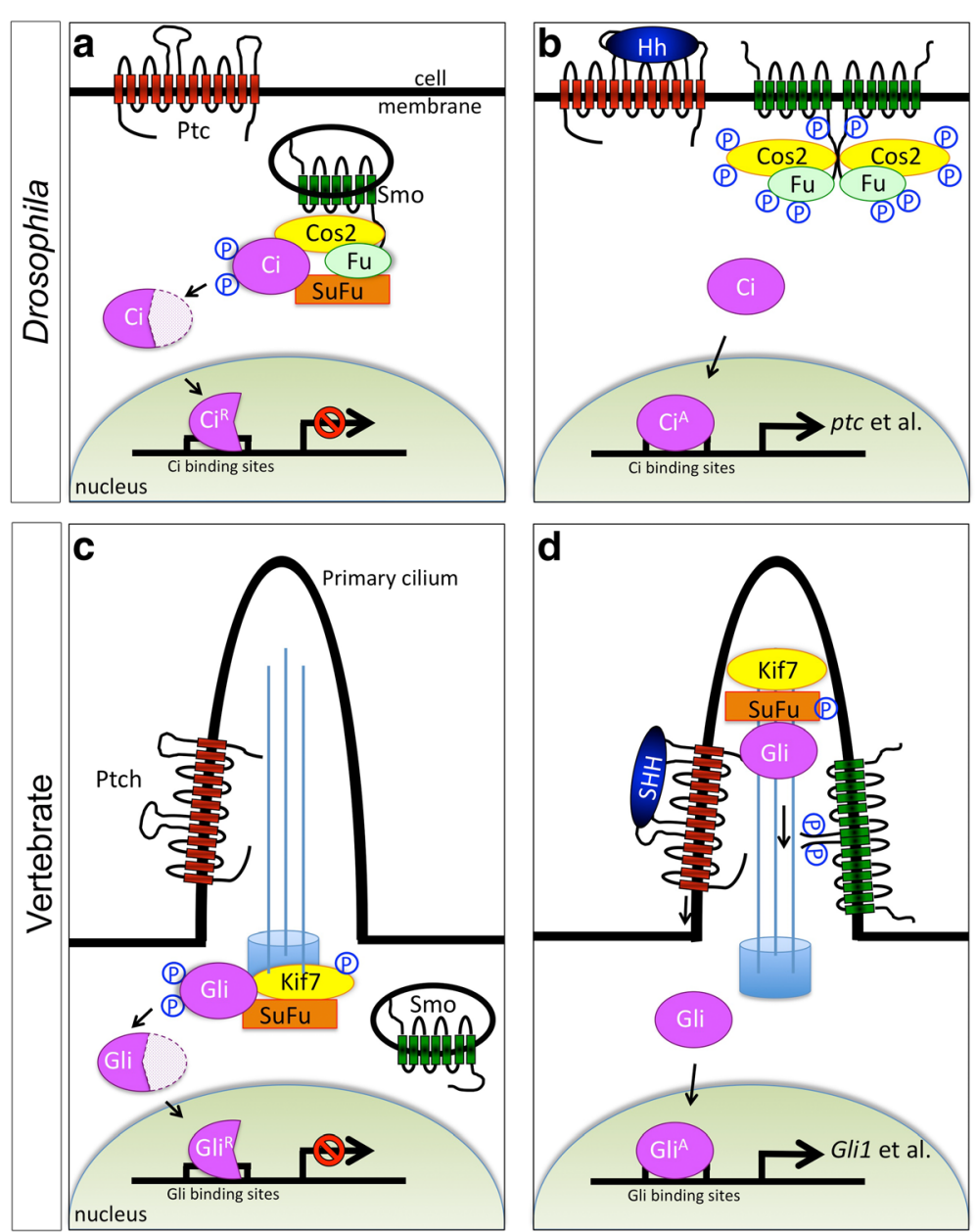

Fig. 1 Schematic of Hh signal transduction in Drosophila and vertebrates. a and $\mathbf{b}$ In Drosophila, without Hh ligand, the phosphorylated transcription factor $\mathrm{Ci}$ undergoes proteolytic cleavage to produce a truncated form as a repressor for target gene transcription (a). With Hh, the pathway activator Smo is relieved from receptor Ptc inhibition to get phosphorylation and plasma membrane accumulation, which triggers a series of phosphorylation events on Cos2 and Fu. Eventually, full-length $\mathrm{Ci}$ is stabilized to enter nucleus activating target gene expression (b). c and $\mathbf{d}$ In vertebrates, the principal rule of Hh signal transduction is conserved. However, several differences are indeed existing: signaling activation takes place at the primary cilia instead of plasma membrane, Sufu plays a more critical role to transduce signal rather than $\mathrm{Fu}$, and Cos 2 homolog Kif7 obtains phosphorylation at basal condition but not during Hh signal activation 
Table 1 Core components of Hh pathway in Drosophila and vertebrates

\begin{tabular}{|c|c|c|c|}
\hline Component Function & Protein Type & Drosophila Protein & Vertebrate Protein \\
\hline Ligand & Secreted protein & Hedgehog $(\mathrm{Hh})$ & $\begin{array}{l}\text { Sonic Hedgehog (Shh), } \\
\text { Desert Hedgehog (Dhh), } \\
\text { Indian Hedgehog (lhh) }\end{array}$ \\
\hline Receptor & 12-transmembrane protein & Patched (Ptc) & $\begin{array}{l}\text { Patched1 (Ptch1), } \\
\text { Patched2 (Ptch2) }\end{array}$ \\
\hline $\begin{array}{l}\text { Transcriptional activator } \\
\text { and repressor }\end{array}$ & Zinc finger transcription factor & Cubitus interruptus (Ci) & $\begin{array}{l}\text { Glioma-associated oncogene } \\
\text { homologue (Gli1-3) }\end{array}$ \\
\hline Signal activator & $\begin{array}{l}\text { 7-transmembrane protein, } \\
\text { G-protein-coupled-receptor (GPCR) }\end{array}$ & Smoothened (Smo) & Smo \\
\hline \multirow[t]{3}{*}{ Signal transducer } & Kinesin-like protein & Costal2 (Cos2) & Kinesin family member 7 (Kif7) \\
\hline & Ser/Thr Kinase & Fused (Fu) & Fu/STK36 \\
\hline & PEST domain protein & $\begin{array}{l}\text { Suppressor of Fused } \\
\text { (Sufu) }\end{array}$ & Sufu \\
\hline
\end{tabular}

[18]. This complication can be representatively reflected by the diverse functions of Glioma-associated oncogene homologue (Gli) proteins, the $\mathrm{Ci}$ homologous proteins in vertebrates. Three members are known in Gli family: Gli1, Gli2, and Gli3. Gli1 mainly serves as a target gene of Hh signaling. Gli2 and Gli3 share the transcriptional task of $\mathrm{Ci}$ in $\mathrm{Hh}$ signaling: Gli2 preferredly contributes to the activator form GliA, and Gli3 is the major source of repressor form GliR [19, 20].

Distinct from Drosophila membrane-mediated $\mathrm{Hh}$ pathway, vertebrate Hh pathway is transduced in a manner depending on primary cilium, a microtubule-based membrane protrusion and antenna-like cellular structure, although the exact biochemical mechanisms remain largely unclear (Fig. $1 \mathrm{c}$ and d) [1]. Hh-induced Smo accumulation on primary cilia and the following transportation of Gli proteins to tips of cilia are prerequisite steps for Gli nucleus translocation. As most Drosophila cells lack cilium structure during development, it was thought that cilia-mediated $\mathrm{Hh}$ signaling is restricted within vertebrates. However, intriguingly, a cilia-mediated Hh pathway in Drosophila olfactory sensory neurons was characterized recently [21], indicating that ciliary Hh pathway is also conserved in Drosophila system.

\section{Major phosphorylation events in Hh pathway: A kinase view}

Protein phosphorylation represents one of the most common post-translational modifications in eukaryotes. Not surprisingly, it also occurs on multiple components during Hh signal transduction [7]. During the past decades, phosphorylation events in Hh pathway have been extensively studied, mainly focusing on the characterization of executing kinases [8], reflecting a fine-tuned responding mechanism for cellular components to precisely transduce Hh signal.

Smo, a seven-pass transmembrane protein with a long carboxyl-terminal intracellular tail, is one of the best- studied components for phosphorylation modification in Hh pathway. Upon Hh stimulation, Smo protein undergoes multiple phosphorylations at its intracellular tail [22], by which Smo is activated to transduce signals towards downstream effectors. In Drosophila, a sequential phosphorylation by cAMP-dependent protein kinase (PKA) and casein kinase I (CK1) [22-24] is the most critical step to inhibit Smo ubiquitination and its subsequent endocytosis and degradation [25, 26], resulting in Smo cell surface accumulation. Moreover, these PKACK1 phosphorylations drive a conformation switch of Smo cytoplasmic tail from a closed inactive to an open active form [27], facilitating Smo maximal phosphorylation by other kinases, such as G-protein-coupled receptor related kinase 2 (GRK2/Gprk2) and CKI / Gilgamesh(Gish) [28-32], to achieve full activation of Smo. However, these PKA-CK1 clusters are not found at vertebrate Smo. Instead, GRK2 and CK1 were thought to replace the role of PKA-CK1 in activating vertebrate Smo by promoting its ciliary localization and active conformation [28, 29, 31, 33-36].

$\mathrm{Ci} / \mathrm{Gli}$ protein, the transcription effector of Hh pathway, is another key component modulated by phosphorylations, and its phosphorylation events exhibit high conservation between Drosophila and vertebrates. It has been well established that multiple-sites phosphorylations on Ci/Gli by PKA, PKA-primed CK1, or PKAprimed glycogen synthase kinase 3 (GSK3), when Hh signal is off, facilitate the recruitment of Cullin1-based E3 ubiquitin ligase complex containing a F-box protein Slimb (Drosophila) or $\beta-\operatorname{TrCP}$ (vertebrates), producing a truncated transcriptional repressor $\mathrm{CiR} / \mathrm{GliR}$ through proteolytic processing [37-45]. In contrast, when Hh signal is switched on, the transcriptional activator form of $\mathrm{Ci} / \mathrm{Gli}$, converted from full-length $\mathrm{Ci} / \mathrm{Gli}$, is eventually subject to complete degradation catalyzed by another Cullin3-based E3 ubiquitination ligase complex that contains HIB/Roadkill (Drosophila) or SPOP (vertebrates) 
[46-48]. The association between $\mathrm{Ci} / \mathrm{Gli}$ and HIB/SPOP can be disrupted by CK1-mediated phosphorylation at multiple serine/threonine-rich degrons on $\mathrm{Ci} / \mathrm{Gli}$, which are distinguished from those PKA-primed CK1 sites, as a consequence, protecting CiA/GliA from premature degradation [49]. Additionally, several other kinases, such as atypical protein kinase $\mathrm{C}(\mathrm{aPKC})$, casein kinase 2 (CK2), dual-specificity tyrosine phosphorylation-regulated kinases (DYRKs), were also implicated in the regulation of $\mathrm{Ci} / \mathrm{Gli}$ activity [50-53].

The cytoplasmic Cos2-Fu-Sufu complex serves as a bridge between $\mathrm{Smo}$ and $\mathrm{Ci} / \mathrm{Gli}$ to transduce $\mathrm{Hh}$ signaling from cell surface to nucleus [54-56]. In response to Hh signal, in Drosophila, Fu kinase phosphorylates Cos2 and Sufu proteins, very likely in a direct manner, to trigger the dissociation of Cos2-FuSufu-Ci complex [55, 57-60], promoting Ci release from the complex and its subsequent activation [57, 61]. Fu itself is also subject to phosphorylation to obtain full activity, including autophosphorylation and its primed CK1 phosphorylation [54, 55, 57, 62, 63]. In mammals, Fu homologs have been suggested as two proteins STK36/Fu and Ulk3. However, it is unlike that they function similarly as $\mathrm{Fu}$ in phosphorylating Cos2 and Sufu, as mouse STK36/Fu appears to be dispensable for embryonic development $[64,65]$ and Ulk3 phosphorylates Gli proteins in vitro [66, 67]. Instead, an unknown kinase phosphorylates vertebrate homologous protein of Cos2, kinesin superfamily member 7 (Kif7) [68], while PKA and GSK3 control mammalian Sufu phosphorylation [69].

\section{The emerging study of phosphatase in Hh pathway}

In contrast to kinases, the participation of phosphatase in Hh pathway and the underlying mechanistic details are poorly understood. Recently, increasing evidence is reported to imply an equally important role of the phosphatase to kinase for the modulation of Hh signaling. According to the type of targeting phosphor-residue, protein phosphatases are classified into three major groups: tyrosine phosphatase, serine/threonine phosphatase, and dual-specificity phosphatase [70]. To date, the majority of known phosphorylation events in $\mathrm{Hh}$ pathway are taking place at serine or threonine residues [7]. Correspondingly, protein serine/threonine phosphatases currently attract most attentions in the studies of phosphatase function during $\mathrm{Hh}$ signal transduction.

\section{Protein phosphatase 1}

Protein phosphatase 1 (PP1) belongs to serine/threonine phosphatase family, and together with protein phosphatase 2A (PP2A), accounts for more than $90 \%$ of protein phosphatase activities in eukaryotes [71]. As such an abundant phosphatase, it is not surprising that PP1 can regulate Hh signal. Actually, the biochemical and genetic studies in Drosophila cultured cells and wing imaginal discs have systematically demonstrated that PP1 negatively modulates $\mathrm{Hh}$ signaling activities through specifically reverting PKA-mediated phosphorylation of Smo protein [72]. The role of PP1 as a phosphatase regulator for Hh pathway was also uncovered in a genome-wide in vivo RNA interference (RNAi) screen searching for kinases and phosphatases that regulate Wnt and/or $\mathrm{Hh}$ signaling pathways [73].

Drosophila genome encodes four PP1 catalytic subunits (PP1c) by two subtypes of genes: $P P 1 \alpha$ and $P P 1 \beta$ $[74,75]$. Three genes encoding $P P 1 \alpha$ isozymes are named as $P p 1-13 C, P p 1-87 B$, and Pp1-96A, according to their chromosomal locations. The fourth gene, flapwing $(f l w)$, codes for PP $1 \beta$ subtype. Smo was detected to interact with all four PP1cs in cultured cells, and individually knocking down these PP1cs by RNAi induced similar levels of Smo phosphorylation [72]. However, regarding specificity of each PP1c in regulating Hh signal activities, Flw seems to act as a positive regulator of $\mathrm{Hh}$ pathway, whereas three of PP $1 \alpha$ isozymes were observed to negatively modulate $\mathrm{Hh}$ signaling outcomes represented by Hh-responsive gene expressions [73]. Even though the mechanism underlying these distinguished effects is not clear, these functional differences between PP $1 \alpha$ and PP1 $\beta / F l w$ have been found in other contexts. For examples, Flw, but not PP1 $\alpha$, binds to Drosophila myosin phosphatase targeting subunit MYPT-75D, functioning as a non-muscle myosin phosphatase to dephosphorylate the nonmuscle myosin regulatory light chain Spaghetti Squash (Sqh) [76]. Furthermore, PP1 $\alpha$ does not rescue semi-lethality of $f l w$ mutants, and Flw also does not rescue $P P 1 \alpha$ double mutants, suggesting non-redundant functions of $\mathrm{PP} 1 \alpha$ and $\mathrm{PP} 1 \beta / \mathrm{Flw}$ during development [77].

\section{Protein phosphatase $2 \mathrm{~A}$}

PP2A is a highly and broadly expressed phosphatase in eukaryotes with the involvements in a wide range of biological processes [6]. In special, PP2A was thought to act as a tumor suppressor, which was initially indicated by the discovery of its inhibitor okadaic acid as a potent tumor promoter, later supported by the finding of its interaction with oncoproteins $[78,79]$. Thus far, PP2A is the most frequently studied seine/threonine phosphatase in Hh pathway. PP2A was initially linked to Hh signaling in mammalian cultured cells [80]. In this study, inhibiting PP2A activity by okadaic acid treatment blocks the expression of COUP-TFII, a Gli-independent Shh responsive target. Consistently, PP2A catalytic subunit overexpression mimics Shh stimulation to induce this target expression. In Drosophila, PP2A also appears to be required in Hh pathway. Microtubule star (mts), 
which encodes the unique PP2A catalytic subunit in flies, was identified as a gene required for maximal $\mathrm{Hh}$ signaling activation from an in vitro RNAi screen in cl-8 cultured cells [81]. In this study, knocking-down $m$ ts resulted in the reduction of Hh-induced reporter activity. Consistently, in a deficiency screen for genomic regions that enhance or suppress a smo partial loss-of-function wing vein phenotype, $m t s$ was found to positively regulate $\mathrm{Hh}$ signaling due to the observation that $m t s$ lossof-function mildly enhanced the smo knock-down (RNAi) phenotype [82]. In a more recent genome-wide in vivo RNAi screen for the phosphor-regulators of multiple signaling pathways, the involvement of PP2A in $\mathrm{Hh}$ signaling pathway was indicated again [73].

The clue for clarifying PP2A targets in Hh pathway has been obtained from a $m t s$ overexpression study [81], in which overexpressing $m t s$ doubled Hh-responsive reporter activity in Hh-uninduced cells but reduced the reporter activity in half in Hh-stimulated cells. Interestingly, PKA showed similar effects on Hh reporter activity as that of $m t s$, suggesting a possibility that PKA and PP2A act on similar substrates. As described above, both Smo and $\mathrm{Ci}$ have been characterized as the substrates of PKA [7]. PP2A may similarly modulate both Smo and Ci dephosphorylations. Indeed, more intensive studies have demonstrated that PP2A plays multiple roles in dictating signaling output by regulating $\mathrm{Smo}, \mathrm{Ci} / \mathrm{Gli}$, and even Cos2/Kif7 [72, 83-86].

\section{PP2A regulates $\mathrm{Ci} / \mathrm{Gli}$ with elusive molecular mechanisms}

As the transcription factor of Hh pathway, Ci/Gli activity is extremely critical for Hh signaling outcomes. PP2A has been implicated to affect almost every steps of $\mathrm{Ci} /$ Gli activation, including $\mathrm{Ci} / \mathrm{Gli}$ protein phosphorylation, proteolytic processing, nuclear localization, transcriptional activity and degradation, in an either direct or indirect manner. In Drosophila, PP2A promotes Ci dephosphorylation and attenuates $\mathrm{Ci}$ cleavage, therefore, positively regulating Hh signaling outputs [83], which is consistent with the results from previous screen studies [81, 82]. In vertebrates, PP2A likely regulates Gli in a different way. In a variety of mammalian cancer cell lines with self-activated Shh signaling, increasing PP2A activity led to cytosolic retention of full-length Gli3 and its decreased transcription activity, while inhibition of PP2A enhanced Gli3 nuclear accumulation and its transcriptional activity $[85,86]$. This negative regulation of PP2A in Gli3 transcriptional activity conflicts with the knowledge that Gli3 undergoes phosphorylation-dependent cleavage to produce a transcriptional repressor of target genes, strongly arguing against the direct mode of PP2A regulation in Gli3 localization and activity, and suggesting a possible involvement of other PP2A-modified factors in Hh pathway. As supporting evidence, PP2A was found to indirectly down-regulate the stability of Gli proteins by controlling the dephosphorylation of Dzip1 [87], a ciliogenesis regulator known in zebrafish [88].

\section{PP2A dephosphorylates Smo as a checkpoint factor to restrict $\mathrm{Hh}$-induced tissue overgrowth}

In addition to $\mathrm{Ci} / \mathrm{Gli}$, PP2A also modulates Smo phosphorylation and activity. As known, Smo is subject to sequential phosphorylations mediated by PKA and then CK1 in Drosophila in response to graded Hh stimulation [7]. This CK1-mediated hyperphosphorylation of Smo requires a high threshold of $\mathrm{Hh}$ signal, promotes Smo trafficking to plasma membrane, and confers Smo maximal activity to activate downstream signal transduction. PP2A was demonstrated to specifically counteract with CK1 to dephosphorylate Smo, consequently, blocking Hh-induced Smo membrane accumulation and target gene expressions [72]. Theoretically, PP2A is capable of serving as a checkpoint factor to restrict the inappropriate signal activities induced by overdosed $\mathrm{Hh}$ signal. However, this PP2A action on Smo dephosphorylation in Drosophila might not be conserved in vertebrate system, because these PKA-primed CK1 consensus sites are not found on vertebrate Smo. Consistently, okadaic acid treatment of MEFs was not able to alter the Hh-dependent localization of Smo in cilia [84]. Instead, another $\mathrm{Hh}$ pathway component Cos $2 / \mathrm{Kif7}$ was discovered as a direct PP2A substrate in vertebrates.

\section{PP2A dephosphorylates Kif7 as a positive effector on vertebrate Hh signaling}

PP2A inhibitor okadaic acid inhibits Kif7 trafficking in cilia and blocks Hh signaling [84]. Conserved with Cos2, the phosphorylation of Kif7 directs its subcellular localization and the transcriptional output of $\mathrm{Hh}$ pathway. However, unlike Cos2, Kif7 is phosphorylated under basal conditions and is dephosphorylated in response to Hh signaling [84]. Mass-spectrum analysis has identified three phosphorylation sites on mouse Kif7, of which Ser1337 is a most critical site for Kif7 cilia localization and Hh signaling activation [84]. Indeed, PP2A exactly dephosphorylates this residue of Ser1337 at mouse Kif7 in the presence of Hh signal, triggering Kif7 localization to the tips of primary cilia and inducing the Glimediated transcriptional output of $\mathrm{Hh}$ signaling [84]. However, it remains unclear whether PP2A regulates Cos2 in fly. In addition, the kinase responsible for Kif7 phosphorylation remains to be uncovered. Although Cos2 phosphorylation is Fu-dependent in Drosophila, mouse Fu appears to play no role in Kif7 phosphorylation $[60,64]$. 


\section{PP2A substrate selection is controlled by its distinct regulatory subunits}

The existence of multiple PP2A targets in Hh pathway raised an important question of how PP2A selects its substrate. The character of PP2A functioning as a heterotrimeric complex might be the key to answer this question. Protein phosphatase counteracts kinase to modulate the phosphorylation status of substrate protein. In mammals, there are around 400 serine/threonine kinases, but intriguingly, there are only about 40 protein serine/threonine phosphatases [71, 89]. Such efficient employment of protein serine/threonine phosphatases in counteracting kinases is achieved by forming numerous multimeric holoenzymes with other interacting partners, each with its own substrates and mode of regulation. This concept of holoenzyme has been well illustrated for PP2A [71]. PP2A holoenzyme is a heterotrimeric complex, composed of a scaffolding subunit, a regulatory subunit and a catalytic subunit, of which the number of regulatory subunits is much higher than that of scaffolding or catalytic subunit (Fig. 2 a and b) [90]. Through the combinatorial association of multiple subunits, and with the existence of alternative splicing, PP2A achieves a large diversity of holoenzyme composition [91]. The crystal structure analysis of PP2A heterotrimeric holoenzyme has revealed that highly acidic concave side of regulatory subunit, towards the active sites of catalytic subunit, outlines a docking pocket to recruit substrate proteins [92]. Different regulatory subunit possesses distinguished charged concave surface, allowing distinct substrate proteins fitting into the docking region (Fig. 2a). Therefore, the regulatory subunit of a PP2A trimeric complex confers the substrate specificity of PP2A holoenzyme.
As PP2A seems to target more than one component in Hh pathway, thereby, the roles of PP2A regulatory subunits in recognizing distinct substrates in $\mathrm{Hh}$ pathway were explored. In mammals, three major PP2A regulatory subunit families, B/B55, B'/B56, and B"/PR72, have been classified (Fig. 2b), of which B56 family comprises the largest and most conserved regulatory subunit family [93]. Five B56 family members have been identified in mammals, including $\alpha, \beta, \gamma, \delta$, and $\varepsilon$. Depletion of B56 $\varepsilon$ in Xenopus embryos reduced the Shh-induced target gene ptc-1 expression, indicating that $\mathrm{B} 56 \varepsilon$ is required for Hh signaling activity [94]. More analysis showed that Hh pathway upstream of Gli remains intact in B56عdepleted embryos, further demonstrating that B56ع likely regulates Hh pathway at the level of Gli during Xenopus development [94].

In Drosophila, four regulatory subunits are encoded: Twins (Tws) represents B55 family, Widerborst (Wdb) and Well-rounded (Wrd) belong to B56 family, and CG4733 is the member of PR72 family. According to the evolutional analysis, B56 family members can be further divided into two clades: Wdb/B56 $\alpha \beta \varepsilon$ and $\mathrm{Wrd} / \mathrm{B} 56 \gamma \delta$ [91]. In consistent with B56e functions in Xenopus, Wdb was first identified as a phosphor-regulator of $\mathrm{Hh}$ pathway from a genome-wide RNAi screen [81], then Wdb-containing PP2A was found to prevent $\mathrm{Ci}$ phosphorylation and proteolytic processing [83]. However, Wdb failed to be immunoprecipitated with $\mathrm{Ci}$ and did not affect $\mathrm{Ci}$ cellular localization [72]. Instead, Tws from B55 family, which has previously been associated with Wnt/Wingless signaling [95], is able to interact with $\mathrm{Ci}$ and promote $\mathrm{Ci}$ nuclear localization [72], suggesting that Tws and Wdb may play distinct roles to modulate $\mathrm{Ci}$ phosphorylation and localization. In terms of Smo

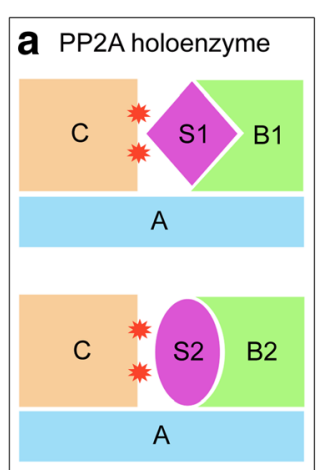

\begin{tabular}{|c|c|c|c|c|}
\hline \multicolumn{5}{|c|}{ Summary of PP2A subunits } \\
\hline Subunit & \multicolumn{2}{|c|}{ Drosophila } & \multicolumn{2}{|c|}{ Mammals } \\
\hline scaffolding A & (1) & CG17291 & (2) & $A \alpha, \beta$ \\
\hline catalytic C & (1) & Mts & (2) & $\mathrm{C} \alpha, \beta$ \\
\hline \multirow{4}{*}{ regulatory $B$} & & Tws & \multirow{4}{*}{$(>20)$} & $\mathrm{B} 55 \alpha, \beta, \gamma, \delta$ \\
\hline & (4) & & & $\mathrm{B} 56 \alpha, \beta, \varepsilon$ \\
\hline & & Wrd & & 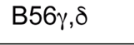 \\
\hline & & CG4733 & & PR72 \\
\hline
\end{tabular}

Fig. 2 Subunit composition of PP2A holoenzyme. a PP2A holoenzyme is a heterotrimeric complex, consisting of three subunits: a scaffolding subunit $A$, a regulatory subunit $B$, and a catalytic subunit $C$, in which $B$ subunit confers the specificity of substrates, by providing distinguished docking surfaces (represented by B1 and B2) towards the active sites (indicated by red asterisks) of C subunit, to allow the binding of specific substrate proteins (S1 and S2, respectively). b Drosophila genome encodes a single A subunit and a single C subunit, but four B subunits. In mammals, there are two A subunits, two $C$ subunits, and more than 20 B subunits. The B subunits are classified into at least three families: B55, $B 56$, and PR72, of which B56 family includes the largest number of members, and is further divided into two subgroups: Wdb/a, $\beta, \varepsilon$ and Wrd/ $/, \delta$. The diversity of B subunit contributes to the selection of various PP2A substrates. Tws, Twins; Wdb, Widerborst; Wrd, Well-rounded 
dephosphorylation, Wdb-containing PP2A holoenzyme counteracts with CK1 to control Smo hyperphosphorylation status, by which $\mathrm{Wdb}$ negatively modulates Smo cell surface accumulation and Hh signaling activities [72]. And this PP2A regulation on Smo is specifically controlled by Wdb, as manipulating Tws, Wrd, or CG4733 expression failed to alter Smo cellular localization and phosphorylation [72]. Therefore, PP2A regulatory subunits exhibit specific preferences in the formation of distinct PP2A holoenzyme to dephosphorylate Smo or Ci in Drosophila.

\section{Protein phosphatase 4}

In addition to PP2A, another known phosphatase regulating Smo is protein phosphatase 4 (PP4). Knocking down pp4 by RNAi was able to promote Smo phosphorylation, but failed to induce Smo cell surface accumulation [83], suggesting that Smo phosphorylation status mediated by PP4 is not sufficient to alter Smo subcellular localization. Interestingly, Cos2 is required for PP4 modulation on Smo [83]. As the direct interaction between PP4 and Cos2 was found, Cos2 may serve as a scaffold to associate PP4 and Smo, allowing the inhibition of Smo phosphorylation by PP4. Later, the involvement of PP4 in Hh pathway was reconfirmed in an in vivo screen [73]. However, these studies did not exclude a possibility that PP4 directly functions on Cos2, therefore indirectly modulate Smo phosphorylation. Further investigation for the bona fide target of PP4 in Hh pathway is expected.

\section{TAP42/ALPHA4}

Alpha4 (Tap42 in yeast) is an atypical regulatory subunit, forming a complex with the catalytic subunit of PP2A, $\mathrm{PP} 4$, or protein phosphatase 6 (PP6). These three phosphatases are evolutionarily related, and together composing a protein serine/threonine phosphatase type 2A family [96-98]. The interaction between Alpha4 and each phosphatase catalytic subunit is independent of their canonical scaffolding and regulatory subunits [96, 97]. Alpha4 plays an important role in regulating the assembly and maintenance of PP2A phosphatase complexes, and its deletion leads to progressive loss of all PP2A, PP4 and PP6 phosphatase complexes [99]. RNAi-mediated silencing of alpha4 altered the expressions of Hh signal related factors in Drosophila wing imaginal discs. The alpha4 RNAi-induced effects were resulted from the loss of regulation of PP2A family members, as enforced expression of wild type alpha4, but not a phosphatase binding defective alpha4 mutant, rescued the defective wing phenotypes [100], suggesting an essential role of Alpha4regulated PP2A family phosphatase in Hh signal and wing development.

\section{Wild-type P53-induced phosphatase 1}

Wild-type p53-induced phosphatase 1 (WIP1 or PPM1D) is a nuclear serine/threonine phosphatase expressed at low levels in most normal tissues [101]. In recent years, WIP1 has emerged as an important player in tumorigenesis [102]. The initial link between WIP1 and Hh signaling was established from a tumorigenesis study [103], in which ectopic expression of WIP1 enhances tumor formation in a Shh-dependent mouse model of medulloblastoma, one of most common tumors caused by improper Hh activity. A later study further elucidated the possible mechanism of WIP1 involving in Hh signaling [104]. Besides p53 as the known WIP1 target, Gli1 was also subject to the regulation from this phosphatase. WIP1 positively modulates Hh signaling by enhancing Gli1 transcriptional activity, nuclear localization, and protein stability. This modulation of Gli1 depends on WIP1 phosphatase activity and is p53-independent. It still remains mysterious whether WIP1 dephosphorylates Gli1 directly or indirectly through a third party.

\section{Lipid phosphatase}

In addition to proteins, lipids are also subject to the regulation by phosphatase. Lipids, such as phosphoinositols, are major constitutes of plasma membrane and cellular organelle membrane, such as ciliary membrane. Given the importance of membranes in either Drosophila Hh pathway or vertebrate ciliary Hh pathway, it is worthy to note recent studies about the requirement of lipid phosphatases for normal Hh signal transduction $[105,106]$. Primary cilium is a unique organelle for vertebrate $\mathrm{Hh}$ signal interpretation. Ciliary membrane contains a particular phosphoinositide, PI(4)P, whereas a different phosphoinositide, $\operatorname{PI}(4,5) \mathrm{P}_{2}$, is located at the membrane of the ciliary base [106]. The level of $\mathrm{PI}(4,5) \mathrm{P}_{2}$ at ciliary membrane is restricted by Inpp5e, a ciliary phosphoinositide 5-phosphatase, who selectively removes the phosphate from position $d-5$ of the inositol ring of phosphoinositides and inositol phosphates [107, 108]. In the inpp5e-deficient cilium, $\mathrm{PI}(4,5) \mathrm{P}_{2}$ level is elevated and Hh signaling is disrupted [106]. In addition to defining lipid distribution, Inpp5e limits the ciliary localization of a $\mathrm{PI}(4,5) \mathrm{P}_{2}$-binding protein, Tubby-like protein 3 (Tulp3), and its interacting proteins, intraflagellar transport complex A (IFT-A) and G-proteincoupled receptor Gpr161, all of which are negative regulators of $\mathrm{Hh}$ signaling [106, 109-113]. In Drosophila, although most cells are lacking cilium structure, $\mathrm{PI}(4) \mathrm{P}$ is also critical for Hh signal transduction [105]. Hh-induced Smo release from Ptc inhibition and subsequent activation are dependent on the levels of PI(4)P. Correspondingly, another lipid phosphatase Suppressor of actin-1 (Sac1), which dephosphorylate PI(4)P, genetically functions downstream of Ptc in the regulation of 
Smo membrane localization and Hh pathway activation. Loss of Sac1 phosphatase results in hh gain-of-function phenotypes [105]. Together, different from the protein phosphatases mentioned above, lipid phosphatases, such as Inpp5e and Sac1, generate a specialized environment by controlling the protein/lipid composition at ciliary or plasma membrane, to facilitate Hh signal transduction.

\section{Phosphatase and HH morphogenetic response}

As a morphogen, Hh protein distributes over cells with a concentration gradient, which induces the different thresholds of signal cellular response in signal receiving cells, and eventually patterns the development of respective tissue or organs. During Hh signal transduction, phosphorylation has been implied to act as an important mechanism to not only fine-tune every component activity, but also interpret $\mathrm{Hh}$ morphogen gradient into graded downstream outcomes (Fig. 3).

The progressive Smo phosphorylations controlled by PKA-PP1 and CK1-PP2A have been illustrated to interpret morphogenic Hh signals into graded signaling outputs, which usually is represented by distinct thresholds of Hhresponsive gene expressions (Fig. 3) [72]. In responding to increasing Hh gradient, Smo obtains PKA-mediated intermediated level of phosphorylation and then CK1-regulated hyperphosphorylation [23]. The mutagenesis analyses have revealed that PKA-phosphorylated Smo species are sufficient to activate low-to-intermediate, but not high, threshold of Hh-responsive gene expressions, whereas PKA-primed CK1 phosphorylation is able to stabilize Smo at plasma membrane and induce the expression of highthreshold Hh target genes [23, 24, 72]. Correspondingly, by antagonizing kinase activities, PP1 or PP2A is capable of regulating the status of Smo phosphorylation and altering the expressions of Hh target genes [72]. Inhibiting the activities of all four PP1cs by nuclear inhibitor of protein phosphatase 1 (Nipp1), an endogenous inhibitor of PP1, is able to enrich PKA-phosphorylated Smo species, and induce the expressions of $\mathrm{Ci}$ and $d p p$, which are responding to low-tointermediate Hh signals. Repression of PP2A activity is able to enhance Smo hyperphosphorylation by CK1 and activate the expression of $p t c$, a high-threshold Hh target gene.

In Hh pathway, Smo does not physically interact with either ligand Hh or receptor Ptc, therefore, the mechanism of how Smo obtains an order from Hh to undergo phosphorylation is not clearly characterized. Yavari et al. have proposed a model that Hh-Ptc binding alters the levels of PI4P at cell membrane to in turn regulate Smo plasma membrane localization and activation [105]. Even though, the relationship between membrane lipids and Smo phosphorylation is still elusive. Alternatively, it is possible that Hh regulates Smo phosphorylations through altering the activities of Smo-related kinases or phosphatases. Actually, upon Hh stimulation, the activities of PKA

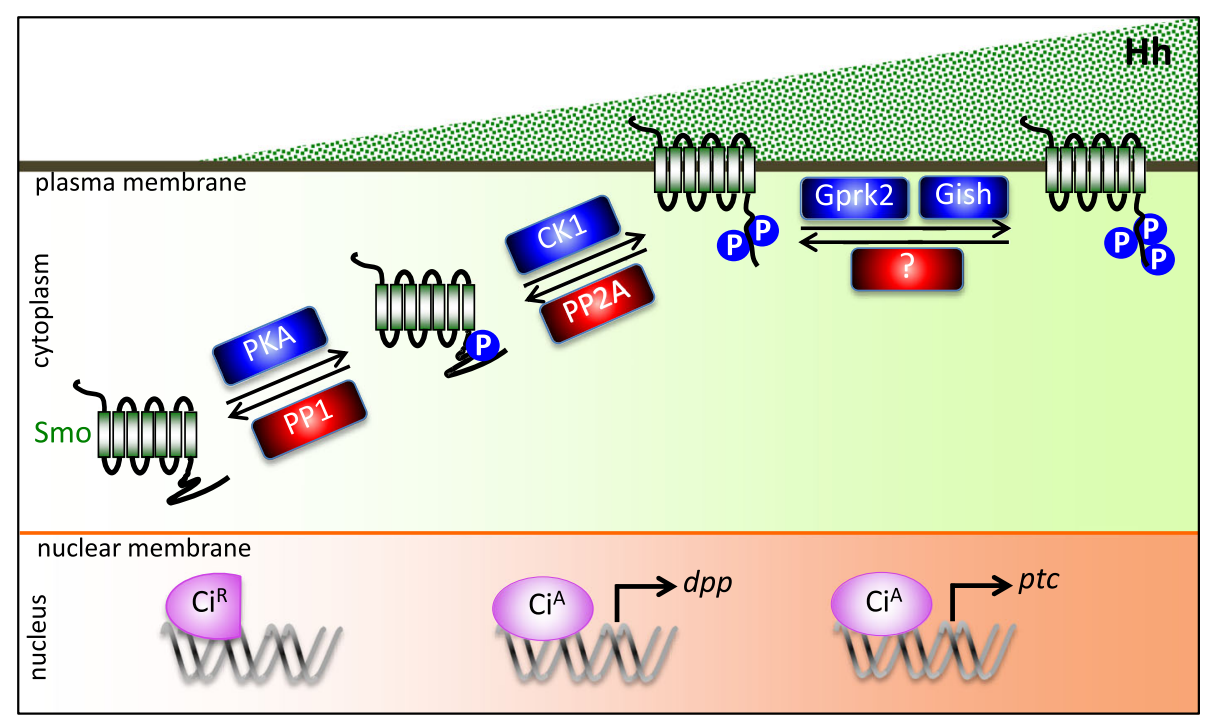

Fig. 3 Multiple kinases-phosphatases mediated progressive Smo phosphorylations interpret morphogenic Hh signals in signal-receiving cells. In response to Hh concentration gradient, Drosophila Smo exhibits graded phosphorylation status, which correspondingly activates the expressions of a series of target genes, such as dpp and ptc, responding to low-to-intermediate threshold, or high threshold Hh signals, respectively. The transcription effector $\mathrm{Ci}$ is switched from a repressor form CiR to an activator form $\mathrm{CiA}$, triggering the expression of Hh target genes. During these progressive Smo phosphorylations, PKA and CK1 sequentially phosphorylate Smo, which promotes Smo accumulation on plasma membrane and facilitates Smo further phosphorylations by Gprk2 and Gish, two kinases preferring the distribution near plasma membrane, to achieve maximal activation of Smo. It has been known that PP1 and PP2A respectively counteract with PKA and CK1 to modulate Smo phosphorylation status. However, the phosphatase against Gprk2 or Gish has not been identified yet 
or CK1 were not obviously changed [72], making it likely that the regulation of PP1 or PP2A activities by Hh could be a major mechanism for Hh-induced Smo phosphorylation. It was observed a long time ago that okadaic acidsensitive-phosphatase activity is induced by Shh treatment in cultured mammalian cells [80]. However, no investigation followed up to further dissect this observation and its underlying molecular mechanism. It will be of interest to delineate the Hh regulation in the expressions or activities of these related phosphatases in future. Regardless, the phosphatase study in Hh signaling has provided a new insight to fully understand the mechanisms of how the morphogenic Hh signals are transduced in cells.

\section{Challenges and opportunities in phosphatase study}

Although the current phosphatase study in Hh pathway has achieved remarkable progress (Fig. 4 a and b), it still falls far behind the kinase study. Up to now, the phosphatases affecting Cos2, Fu, or Sufu, remain mysterious. A few phosphatases have been identified to regulate $\mathrm{Smo}, \mathrm{Ci} / \mathrm{Gli}$, and Kif7. However, the molecular basis of these phosphatase actions, including the specific targeting phosphor-residues on substrates, is largely unclear. The less progress on phosphatase study mainly is resulted from the difficulties apparently existing in this field.

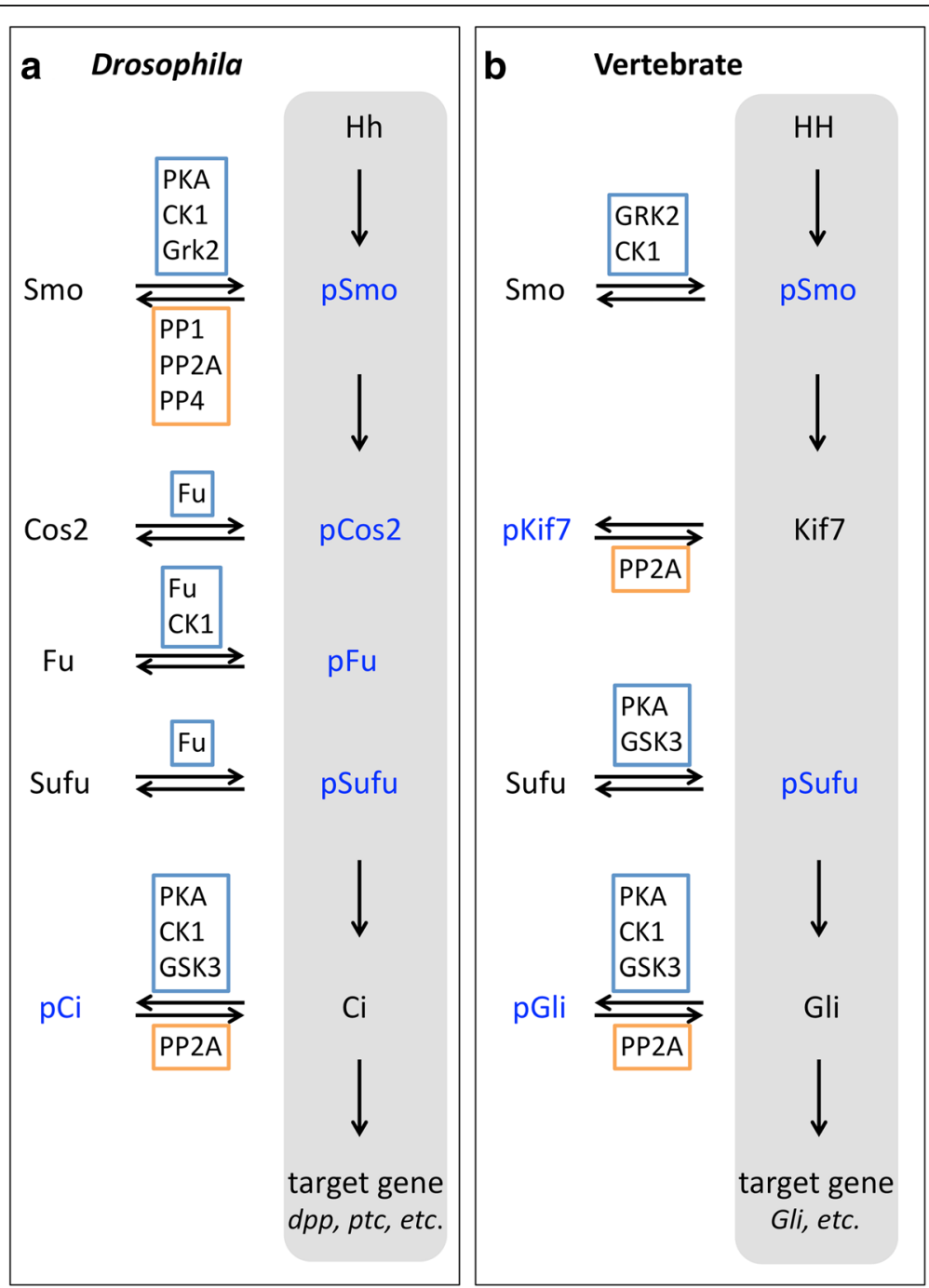

Fig. 4 Summary of major kinases and phosphatases involved in Hh pathway. a In Drosophila, Hh induces the phosphorylations of Smo, Cos2, Fu, and Sufu proteins, but dephosphorylation of protein $\mathrm{Ci}$, which activate the expressions of target genes. b Similarly, vertebrate Smo and Sufu proteins undergo phosphorylations, and Gli proteins undergo dephosphorylation upon $\mathrm{HH}$ stimulation. However, different from Cos 2 in Drosophila, Kif7 is phosphorylated when $\mathrm{HH}$ signal is off, but dephosphorylated when $\mathrm{HH}$ signal is on. The major key kinases and phosphatases controlling these phosphorylation events are shown within blue boxes or orange boxes, respectively. Phosphorylated proteins are highlighted in blue. The signal transduction cascade under Hh condition is indicated with gray background 
First, it is a big challenge to correlate a phosphatase with its substrates if without any clues from experimental studies. Different from kinases that recognize their substrates simply depending on certain specific consensus sequence, a suitable binding of a phosphatase with its substrate relies on many aspects of these two proteins, such as their three dimension structures, conformations, and even the charges of residues. So it is nearly impossible currently to predict a substrate for a particular phosphatase, or search a responsible phosphatase for a known phosphor-protein, solely based on protein sequences. Second, many phosphatases execute functions only by forming complexes with one or more regulatory subunits. The function study for this type of phosphatase complex requires more comprehensive analysis for all components. Due to the high diversity of regulatory subunits, especially in vertebrates, a phosphatase may obtain various functions by binding with distinct regulatory subunits. But on the other side, the existence of multiple regulatory subunits also increases the complexity to delineate the function of a particular phosphatase, such as the occurrence of functional redundancy between different regulatory subunits.

To overcome these obstacles, many attempts have been undertaken. For example, much effort has been made to define a simple principle for the substrate recognition of PP1 or PP2A. A PP1-docking motif with well-defined consensus sequence $\mathrm{RVxF}$ was found to exist in about 70\% of all PP1-interacting proteins including PP1 substrates [114]. For PP2A substrate recognition, a conserved LxxIxE motif was reported recently to provide a binding specificity to a particular PP2A phosphatase complex containing B56 regulatory subunit [115]. Although these motifs cannot fully represent the mechanisms to explain the substrate selection of PP1 or PP2A, it is a good starting point to search for PP1 or PP2A substrates. In addition, to bypass these sequence analysis, an organbased genetic screen with a suitable readout is becoming a reliable way to search for the involved phosphatase under certain circumstances. For instances, several novel phosphatase regulators of $\mathrm{Hh}$ signaling, such as PPV and PpD3, have been identified in a screen through observing the expression pattern of Hh-responsive genes in Drosophila larval wing imaginal discs [73]. However, due to the way of phosphatase functioning as a complex and functional redundancy between different regulatory subunits or isoforms, it is expected that some phosphatase effectors could be missed from this kind of screens. Alternatively, according to the character of a protein serine/threonine phosphatase physically interacting with its substrate, utilizing biochemistry methods to precipitate the interacting proteins with a particular phosphatase could be another feasible approach to search for substrates of phosphatases [116]. With the improving techniques in proteomics and phosphatomics, such as phosphor-protein enrichment and advanced tandem mass spectrometry, identifying substrates for phosphatases through these biochemistry approaches appears to be more achievable now than before.

\section{Conclusions}

During Hh signal transduction cascade, a broader phosphorylation spectrum has been outlined. As one of two key executors in phosphorylation process, the phosphatase has been increasingly studied in Hh pathway, and remarkable progress has been achieved in recent years. Many phosphatases have been identified in regulating Hh signal activities. Even though, the phosphatase study is still far away from the edge of completion. Many of known phosphorylation events in Hh pathway are lacking information of the responsible phosphatase. On the other side, the molecular mechanism by which the identified phosphatase regulators affect $\mathrm{Hh}$ signaling has not been clearly characterized. Fortunately, with the increasing emphasis and improving techniques for phosphatase studies, a more thorough understanding of the phosphatase functions in Hh pathway is promising in the near future.

\section{Abbreviations \\ aPKC: atypical protein kinase C; Cdc211: cell division cycle 2 like protein kinase 1; Ci: Cubitus interruptus; CiA: Ci activator form; CiR: Ci repressor form; CK1: casein kinase 1; CK2: casein kinase 2; Cos2: Costal2; DYRK: dual-specificity tyrosine phosphorylation-regulated kinase; Dzip1: Daz interacting protein 1; Fu: Fused; Gish: Gilgamesh; Gli: Glioma-associated oncogene homologue protein; GPCR: G-protein-coupled receptor; GRK/Gprk: G-protein-coupled receptor kinase; GSK3: glycogen synthase kinase 3; Hh: Hedgehog; HIB: Hh-induced MATH and BTB domain protein; Kif7: kinesin superfamily member 7; MAP3K10: mitogen-activated protein kinase kinase kinase 10; MEF: mouse embryonic fibroblast; OA: okadaic acid; PKA: protein kinase A; PP1: protein phosphatase 1; PP2A: protein phosphatase 2A; PP4: protein phosphatase 4; PPV: protein phosphatase V; Ptc: Patched; RNAi: RNA interference; Ser: serine; SPOP: speckle-type BTB/POZ protein; STK36: serine/threonine protein kinase 36; Sufu: Suppressor of fused; Thr: threonine; Tws: twins; Ulk3: Unc-51 like kinase 3; Wdb: widerborst; WIP1: wild-type p53-induced phosphatase 1; Wrd: well-rounded.}

\section{Acknowledgements}

The authors thank Shan Gao and Hongyan Li in Ocean University of China for their kind support. We also thank the members of Su lab for reading the manuscript and comments.

\section{Funding}

This work was supported by the grants from American Heart Association (12SDG8870002) to Y. Su, and the grants from Fundamental Research Funds for Central Universities, China (201562029 and 201762003).

\section{Availability of data and materials \\ Not applicable.}

\section{Authors' contributions}

YS gave the idea of the review, outlined the content of the review, and made the final corrections for the manuscript. LZ and YS wrote the manuscript and designed the figures and Table. LW, CC and WL drew the figures. All authors read and approved the final manuscript.

Ethics approval and consent to participate Not applicable. 


\section{Consent for publication}

Not applicable.

\section{Competing interests}

The authors declare that they have no competing interests.

\section{Publisher's Note}

Springer Nature remains neutral with regard to jurisdictional claims in published maps and institutional affiliations.

\section{Author details}

${ }^{1}$ Cardiovascular Research Center, Department of Medicine, Massachusetts General Hospital and Harvard Medical School, Charlestown, MA 02129, USA ${ }^{2}$ Institute of Evolution \& Marine Biodiversity, College of Marine Life Sciences, Ocean University of China, Qingdao 266003, China.

\section{Received: 13 July 2017 Accepted: 14 September 2017}

\section{Published online: 20 September 2017}

\section{References}

1. Varjosalo M, Taipale J. Hedgehog: functions and mechanisms. Genes Dev. 2008;22:2454-72

2. Jiang J, Hui CC. Hedgehog signaling in development and cancer. Dev Cell. 2008;15:801-12.

3. Pak E, Segal RA. Hedgehog signal transduction: key players, oncogenic drivers, and cancer therapy. Dev Cell. 2016:38:333-44.

4. Singh V, Ram M, Kumar R, Prasad R, Roy BK, Singh KK. Phosphorylation: Implications in Cancer. Protein J. 2017;36:1-6.

5. Cohen $P$. The regulation of protein function by multisite phosphorylation: a 25 year update. Trends Biochem Sci. 2000:25:596-601.

6. Virshup DM, Shenolikar S. From promiscuity to precision: protein phosphatases get a makeover. Mol Cell. 2009;33:537-45.

7. Chen Y, Jiang J. Decoding the phosphorylation code in hedgehog signal transduction. Cell Res. 2013;23:186-200.

8. Aikin RA, Ayers KL, Therond PP. The role of kinases in the hedgehog signalling pathway. EMBO Rep. 2008;9:330-6

9. Ingham PW. Drosophila segment polarity mutants and the rediscovery of the hedgehog pathway genes. Curr Top Dev Biol. 2016;116:477-88.

10. Marigo V, Davey RA, Zuo Y, Cunningham JM, Tabin CJ. Biochemical evidence that patched is the hedgehog receptor. Nature. 1996;384:176-9.

11. Chen $Y$, Struhl G. Dual roles for patched in sequestering and transducing hedgehog. Cell. 1996;87:553-63.

12. Alcedo J, Ayzenzon M, Von Ohlen T, Noll M, Hooper JE. The drosophila smoothened gene encodes a seven-pass membrane protein, a putative receptor for the hedgehog signal. Cell. 1996;86:221-32.

13. van den Heuvel M, Ingham PW. smoothened encodes a receptor-like serpentine protein required for hedgehog signaling. Nature. 1996;382:547-51.

14. Alexandre C, Jacinto A, Ingham PW. Transcriptional activation of hedgehog target genes in drosophila is mediated directly by the cubitus interruptus protein, a member of the GLI family of zinc finger DNA-binding proteins. Genes Dev. 1996;10:2003-13.

15. Monnier V, Dussillol F, Alves G, Lamour-Isnard C, Plessis A. Suppressor of fused links fused and Cubitus interruptus on the hedgehog signaling pathway. Curr Biol. 1998;8:583-6.

16. Sisson JC, Ho KS, Suyama K, Scott MP. Costal2, a novel kinesin-related protein in the hedgehog signaling pathway. Cell. 1997;90:235-45.

17. Therond P, Limbourg Bouchon B, Gallet A, Dussillol F, Pietri T, van den Heuvel M, Tricoire H. Differential requirements of the fused kinase for hedgehog signaling in the drosophila embryo. Development. 1999:126:4039-51.

18. Wilson CW, Chuang PT. Mechanism and evolution of cytosolic hedgehog signal transduction. Development. 2010;137:2079-94.

19. Huangfu D, Anderson KV. Signaling from Smo to ci/Gli: conservation and divergence of hedgehog pathways from drosophila to vertebrates. Development. 2006;133:3-14.

20. Hui CC, Angers S. Gli proteins in development and disease. Annu Rev Cell Dev Biol. 2011:27:513-37.

21. Kuzhandaivel A, Schultz SW, Alkhori L, Alenius M. Cilia-mediated hedgehog signaling in drosophila. Cell Rep. 2014;7:672-80.

22. Zhang C, Williams E, Guo Y, Lum L, Beachy P. Extensive phosphorylation of smoothened in hedgehog pathway activation. Proc Natl Acad Sci U S A. 2004;101:17900-7.
23. Jia J, Tong C, Wang B, Luo L, Jiang J. Hedgehog signaling activity of smoothened requires phosphorylation by protein kinase a and casein kinase I. Nature. 2004;432:1045-50.

24. Apionishev S, Katanayeva NM, Marks SA, Kalderon D, Tomlinson A. Drosophila smoothened phosphorylation sites essential for hedgehog signa transduction. Nat Cell Biol. 2005;7:86-92.

25. Li S, Chen Y, Shi Q, Yue T, Wang B, Jiang J. Hedgehog-regulated ubiquitination controls smoothened trafficking and cell surface expression in drosophila. PLoS Biol. 2012;10:e1001239.

26. Xia R, Jia H, Fan J, Liu Y, Jia J. USP8 promotes smoothened signaling by preventing its ubiquitination and changing its subcellular localization. PLoS Biol. 2012;10:e1001238.

27. Zhao $Y$, Tong $C$, Jiang J. Hedgehog regulates smoothened activity by inducing a conformational switch. Nature. 2007;450:252-8.

28. Maier D, Cheng S, Faubert D, Hipfner DR. A broadly conserved g-proteincoupled receptor kinase phosphorylation mechanism controls drosophila smoothened activity. PLoS Genet. 2014:10:e1004399.

29. Chen Y, Li S, Tong C, Zhao Y, Wang B, Liu Y, Jia J, Jiang J. G protein-coupled receptor kinase 2 promotes high-level hedgehog signaling by regulating the active state of Smo through kinase-dependent and kinase-independent mechanisms in drosophila. Genes Dev. 2010:24:2054-67.

30. Molnar C, Holguin H, Mayor F Jr, Ruiz-Gomez A, de Celis JF. The G proteincoupled receptor regulatory kinase GPRK2 participates in hedgehog signaling in drosophila. Proc Natl Acad Sci U S A. 2007;104:7963-8.

31. Cheng S, Maier D, Neubueser D, Hipfner DR. Regulation of smoothened by drosophila G-protein-coupled receptor kinases. Dev Biol. 2010;337:99-109.

32. Li S, Li S, Han Y, Tong C, Wang B, Chen Y, Jiang J. Regulation of smoothened phosphorylation and high-level hedgehog signaling activity by a plasma membrane associated kinase. PLoS Biol. 2016;14:e1002481.

33. Chen Y, Sasai N, Ma G, Yue T, Jia J, Briscoe J, Jiang J. Sonic hedgehog dependent phosphorylation by CK1alpha and GRK2 is required for ciliary accumulation and activation of smoothened. PLoS Biol. 2011:9:e1001083.

34. Philipp M, Fralish GB, Meloni AR, Chen W, Maclnnes AW, Barak LS, Caron MG. Smoothened signaling in vertebrates is facilitated by a $\mathrm{G}$ proteincoupled receptor kinase. Mol Biol Cell. 2008;19:5478-89.

35. Meloni AR, Fralish GB, Kelly P, Salahpour A, Chen JK, Wechsler-Reya RJ, Lefkowitz RJ, Caron MG. Smoothened signal transduction is promoted by G protein-coupled receptor kinase 2. Mol Cell Biol. 2006;26:7550-60.

36. Chen W, Ren X-R, Nelson CD, Barak LS, Chen JK, Beachy P, de Sauvage F, Lefkowitz RJ. Activity-dependent internalization of smoothened mediated by b-Arrestin 2 and GRK2. Science. 2004;306:2257-60.

37. Price MA, Kalderon D. Proteolysis of cubitus interruptus in drosophila requires phosphorylation by protein kinase a. Development. 1999;126:4331-9.

38. Price MA, Kalderon D. Proteolysis of the hedgehog signaling effector Cubitus interruptus requires phosphorylation by glycogen synthase kinase 3 and casein kinase 1. Cell. 2002;108:823-35.

39. Jia J, Amanai K, Wang G, Tang J, Wang B, Jiang J. Shaggy/GSK3 antagonizes hedgehog signalling by regulating Cubitus interruptus. Nature. 2002;416:548-52.

40. Jia J, Zhang L, Zhang Q, Tong C, Wang B, Hou F, Amanai K, Jiang J. Phosphorylation by double-time/CKlepsilon and CKlalpha targets cubitus interruptus for Slimb/beta-TRCP-mediated proteolytic processing. Dev Cell. 2005;9:819-30.

41. Smelkinson MG, Kalderon D. Processing of the drosophila hedgehog signaling effector $\mathrm{Ci}-155$ to the repressor $\mathrm{Ci}-75$ is mediated by direct binding to the SCF component Slimb. Curr Biol. 2006:16:110-6.

42. Smelkinson MG, Zhou Q, Kalderon D. Regulation of ci-SCFSlimb binding, ci proteolysis, and hedgehog pathway activity by ci phosphorylation. Dev Cell. 2007;13:481-95.

43. Wang B, Li Y. Evidence for the direct involvement of \{beta\}TrCP in Gli3 protein processing. Proc Natl Acad Sci U S A. 2006;103:33-8.

44. Tempe D, Casas M, Karaz S, Blanchet-Tournier MF, Concordet JP. Multisite protein kinase a and glycogen synthase kinase 3 beta phosphorylation leads to Gli3 ubiquitination by SCFbetaTrCP. Mol Cell Biol. 2006;26:4316-26.

45. Pan $Y$, Bai $C B$, Joyner AL, Wang B. Sonic hedgehog signaling regulates $G$ li2 transcriptional activity by suppressing its processing and degradation. Mol Cell Biol. 2006:26:3365-77.

46. Kent D, Bush EW, Hooper JE. Roadkill attenuates hedgehog responses through degradation of Cubitus interruptus. Development. 2006;133:2001-10.

47. Zhang Q, Zhang L, Wang B, Ou CY, Chien CT, Jiang J. A hedgehog-induced BTB protein modulates hedgehog signaling by degrading $\mathrm{ci} / \mathrm{Gli}$ transcription factor. Dev Cell. 2006;10:719-29. 
48. Zhang Q, Shi Q, Chen Y, Yue T, Li S, Wang B, Jiang J. Multiple Ser/Thr-rich degrons mediate the degradation of ci/Gli by the Cul3-HIB/SPOP E3 ubiquitin ligase. Proc Natl Acad Sci U S A. 2009;106:21191-6.

49. Shi Q, Li S, Li S, Jiang A, Chen Y, Jiang J. Hedgehog-induced phosphorylation by CK1 sustains the activity of ci/Gli activator. Proc Natl Acad Sci U S A. 2014;111:E5651-60.

50. Jia H, Liu Y, Xia R, Tong C, Yue T, Jiang J, Jia J. Casein kinase 2 promotes hedgehog signaling by regulating both smoothened and Cubitus interruptus. J Biol Chem. 2010;285:37218-26.

51. Varjosalo M, Bjorklund M, Cheng F, Syvanen H, Kivioja T, Kilpinen S, Sun Z, Kallioniemi O, Stunnenberg HG, He WW, et al. Application of active and kinase-deficient kinome collection for identification of kinases regulating hedgehog signaling. Cell. 2008;133:537-48.

52. Mao J, Maye P, Kogerman P, Tejedor FJ, Toftgard R, Xie W, Wu G, Wu D. Regulation of Gli1 transcriptional activity in the nucleus by Dyrk1. J Biol Chem. 2002;277:35156-61.

53. Schneider $P$, Bayo-Fina JM, Singh R, Kumar Dhanyamraju P, Holz P, Baier A, Fendrich V, Ramaswamy A, Baumeister S, Martinez ED, Lauth M. Identification of a novel actin-dependent signal transducing module allows for the targeted degradation of GLI1. Nat Commun. 2015;6:8023.

54. Lum L, Zhang C, Oh S, Mann R, Von Kessler D, Taipale J, Weis-Garcia F, Gong R, Wang B, Beachy P. Hedgehog signal transduction via smoothened association with a cytoplasmic complex scaffolded by the atypical kinesin, Costal-2. Mol Cell. 2003;12:1261-74

55. Shi Q, Li S, Jia J, Jiang J. The hedgehog-induced smoothened conformational switch assembles a signaling complex that activates fused by promoting its dimerization and phosphorylation. Development. 2011; 138:4219-31.

56. Jia J, Tong C, Jiang J. Smoothened transduces hedgehog signal by physically interacting with Costal2/fused complex through its C-terminal tail. Genes Dev. 2003;17:2709-20.

57. Zhou Q, Kalderon D. Hedgehog activates fused through phosphorylation to elicit a full spectrum of pathway responses. Dev Cell. 2011;20:802-14.

58. Hooper JE, Scott MP. Communicating with hedgehogs. Nat Rev Mol Cell Biol. 2005;6:306-17.

59. Ingham PW, McMahon AP. Hedgehog signaling in animal development: paradigms and principles. Genes Dev. 2001;15:3059-87.

60. Raisin S, Ruel L, Ranieri N, Staccini-Lavenant L, Therond PP. Dynamic phosphorylation of the kinesin Costal-2 in vivo reveals requirement of fused kinase activity for all levels of hedgehog signalling. Dev Biol. 2010;344:119-28.

61. Ruel L, Gallet A, Raisin S, Truchi A, Staccini-Lavenant L, Cervantes A, Therond PP. Phosphorylation of the atypical kinesin Costal2 by the kinase fused induces the partial disassembly of the smoothened-fusedCostal2-Cubitus interruptus complex in hedgehog signalling. Development. 2007;134:3677-89.

62. Therond P, Knight J, Kornberg T, Bishop J. Phosphorylation of the fused protein kinase in response to signaling from hedgehog. Proc Natl Acad Sci U S A. 1996:93:4224-8.

63. Zhang Y, Mao F, Lu Y, Wu W, Zhang L, Zhao Y. Transduction of the hedgehog signal through the dimerization of fused and the nuclear translocation of Cubitus interruptus. Cell Res. 2011:21:1436-51.

64. Chen MH, Gao N, Kawakami T, Chuang PT. Mice deficient in the fused homolog do not exhibit phenotypes indicative of perturbed hedgehog signaling during embryonic development. Mol Cell Biol. 2005;25:7042-53.

65. Merchant M, Evangelista M, Luoh SM, Frantz GD, Chalasani S, Carano RA van Hoy M, Ramirez J, Ogasawara AK, MCFarland LM, et al. Loss of the serine/threonine kinase fused results in postnatal growth defects and lethality due to progressive hydrocephalus. Mol Cell Biol. 2005;25:7054-68.

66. Maloverjan A, Piirsoo M, Michelson P, Kogerman P, Osterlund T. Identification of a novel serine/threonine kinase ULK3 as a positive regulator of hedgehog pathway. Exp Cell Res. 2010;316:627-37.

67. Maloverjan A, Piirsoo M, Kasak L, Peil L, Osterlund T, Kogerman P. Dual function of UNC-51-like kinase 3 (UIk3) in the sonic hedgehog signaling pathway. J Biol Chem. 2010;285:30079-90.

68. Endoh-Yamagami S, Evangelista M, Wilson D, Wen X, Theunissen JW, Phamluong K, Davis M, Scales SJ, Solloway MJ, de Sauvage FJ, Peterson AS The mammalian Cos2 homolog Kif7 plays an essential role in modulating Hh signal transduction during development. Curr Biol. 2009;19:1320-6.

69. Chen Y, Yue S, Xie L, Pu XH, Jin T, Cheng SY. Dual phosphorylation of suppressor of fused (Sufu) by PKA and GSK3beta regulates its stability and localization in the primary cilium. J Biol Chem. 2011;286:13502-11.
70. Moorhead GB, De Wever V, Templeton G, Kerk D. Evolution of protein phosphatases in plants and animals. Biochem J. 2009;417:401-9.

71. Moorhead GB, Trinkle-Mulcahy L, Ulke-Lemee A. Emerging roles of nuclear protein phosphatases. Nat Rev Mol Cell Biol. 2007:8:234-44.

72. Su Y, Ospina JK, Zhang J, Michelson AP, Schoen AM, Zhu AJ. Sequential phosphorylation of smoothened transduces graded Hedgehog signaling. Science Signaling. 2011;4:ra43.

73. Swarup S, Pradhan-Sundd T, Verheyen EM. Genome-wide identification of phospho-regulators of Wnt signaling in drosophila. Development. 2015;142: 1502-15.

74. Dombradi V, Axton JM, Brewis ND, Da cruz e Silva EF, Alphey L, Cohen PT. drosophila contains three genes that encode distinct isoforms of protein phosphatase 1. FEBS J. 1990;194:739-45.

75. Dombradi V, Mann DJ, Saunders RD, Cohen PT. Cloning of the fourth functional gene for protein phosphatase 1 in Drosophila Melanogaster from its chromosomal location. FEBS J. 1993;212:177-83.

76. Vereshchagina N, Bennett D, Szoor B, Kirchner J, Gross S, Vissi E, WhiteCooper $\mathrm{H}$, Alphey L. The essential role of PP1 b in drosophila is to regulate nonmuscle myosin. Mol Biol Cell. 2004;15:4395-405.

77. Kirchner J, Gross S, Bennett D, Alphey L. Essential, overlapping and redundant roles of the drosophila protein phosphatase 1 alpha and 1 beta genes. Genetics. 2007;176:273-81.

78. Westermarck J, Hahn WC. Multiple pathways regulated by the tumor suppressor PP2A in transformation. Trends Mol Med. 2008;14:152-60.

79. Mumby M. PP2A: unveiling a reluctant tumor suppressor. Cell. 2007;130:21-4.

80. Krishnan V, Pereira FA, Qiu Y, Chen CH, Beachy PA, Tsai SY, Tsai MJ. Mediation of sonic hedgehog-induced expression of COUP-TFIl by a protein phosphatase. Science. 1997;278:1947-50.

81. Nybakken K, Vokes SA, Lin TY, McMahon AP, Perrimon N. A genome-wide RNA interference screen in Drosophila Melanogaster cells for new components of the Hh signaling pathway. Nat Genet. 2005;37:1323-32.

82. Casso DJ, Liu S, Iwaki DD, Ogden SK, Kornberg TB. A screen for modifiers of hedgehog signaling in Drosophila Melanogaster identifies swm and mts. Genetics. 2008:178:1399-413.

83. Jia H, Liu Y, Yan W, Jia J. PP4 and PP2A regulate hedgehog signaling by controlling Smo and ci phosphorylation. Development. 2009;136:307-16.

84. Liu YC, Couzens AL, Deshwar AR, LD BM-C, Zhang X, Puviindran V, Scott IC, Gingras AC, Hui CC, Angers S. The PPFIA1-PP2A protein complex promotes trafficking of Kif7 to the ciliary tip and Hedgehog signaling. Sci Signal. 2014; 7:ra117.

85. Krauss S, So J, Hambrock M, Kohler A, Kunath M, Scharff C, Wessling M, Grzeschik KH, Schneider R, Schweiger S. Point mutations in GLI3 lead to misregulation of its subcellular localization. PLoS One. 2009;4:e7471.

86. Krauss S, Foerster J, Schneider R, Schweiger S. Protein phosphatase 2A and rapamycin regulate the nuclear localization and activity of the transcription factor GLI3. Cancer Res. 2008;68:4658-65.

87. Jin Z, Mei W, Strack S, Jia J, Yang J. The antagonistic action of B56containing protein phosphatase $2 \mathrm{As}$ and casein kinase 2 controls the phosphorylation and Gli turnover function of Daz interacting protein 1. J Biol Chem. 2011;286:36171-9.

88. Arnold C, Lamont R, Walker J, Spice P, Chan C, Ho C, Childs S. Comparative analysis of genes regulated by Dzip1/iguana and hedgehog in zebrafish. Dev Dyn. 2015;244:211-23.

89. Manning G, Plowman GD, Hunter T, Sudarsanam S. Evolution of protein kinase signaling from yeast to man. Trends Biochem Sci. 2002;27:514-20.

90. Seshacharyulu P, Pandey P, Datta K, Batra SK. Phosphatase: PP2A structural importance, regulation and its aberrant expression in cancer. Cancer Lett. 2013;335:9-18.

91. Sommer LM, Cho H, Choudhary M, Seeling JM. Evolutionary analysis of the B56 gene family of PP2A regulatory subunits. Int J Mol Sci. 2015;16:10134-57.

92. Xu Y, Xing $Y$, Chen $Y$, Chao $Y$, Lin Z, Fan E, Yu JW, Strack S, Jeffrey PD, Shi Y. Structure of the protein phosphatase 2A holoenzyme. Cell. 2006; 127:1239-51.

93. Yang J, Phiel C. Functions of B56-containing PP2As in major developmental and cancer signaling pathways. Life Sci. 2010;87:659-66.

94. Rorick AM, Mei W, Liette NL, Phiel C, El-Hodiri HM, Yang J. PP2A: B56epsilon is required for eye induction and eye field separation. Dev Biol. 2007:302:477-93.

95. Bajpai R, Makhijani K, Rao PR, Shashidhara LS. Drosophila twins regulates armadillo levels in response to Wg/Wnt signal. Development. 2004;131:1007-16. 
96. Chen J, Peterson RT, Schreiber SL. Alpha 4 associates with protein phosphatases 2A, 4, and 6. Biochem Biophys Res Commun. 1998;247:827-32.

97. Kloeker S, Reed R, McConnell JL, Chang D, Tran K, Westphal RS, Law BK, Colbran RJ, Kamoun M, Campbell KS, Wadzinski BE. Parallel purification of three catalytic subunits of the protein serine/threonine phosphatase $2 \mathrm{~A}$ family (PP2AC, PP4C, and PP6C) and analysis of the interaction of PP2AC with alpha4 protein. Protein Expr Purif. 2003;31:19-33.

98. Lillo C, Kataya AR, Heidari B, Creighton MT, Nemie-Feyissa D, Ginbot Z, Jonassen EM. Protein phosphatases PP2A, PP4 and PP6: mediators and regulators in development and responses to environmental cues. Plant Cell Environ. 2014;37:2631-48.

99. Kong M, Ditsworth D, Lindsten T, Thompson CB. Alpha4 is an essential regulator of PP2A phosphatase activity. Mol Cell. 2009;36:51-60.

100. Wang N, Leung HT, Mazalouskas MD, Watkins GR, Gomez RJ, Wadzinski BE. Essential roles of the Tap42-regulated protein phosphatase 2A (PP2A) family in wing imaginal disc development of Drosophila Melanogaster. PLoS One. 2012;7:e38569

101. Zhu YH, Bulavin DV. Wip1-dependent signaling pathways in health and diseases. Prog Mol Biol Transl Sci. 2012;106:307-25.

102. Park JY, Song JY, Kim HM, Han HS, Seol HS, Jang SJ, Choi J. p53independent expression of wild-type p53-induced phosphatase 1 (Wip1) in methylmethane sulfonate-treated cancer cell lines and human tumors. Int J Biochem Cell Biol. 2012;44:896-904.

103. Doucette TA, Yang Y, Pedone C, Kim JY, Dubuc A, Northcott PD, Taylor MD, Fults DW, Rao G. WIP1 enhances tumor formation in a sonic hedgehogdependent model of medulloblastoma. Neurosurgery. 2012;70:1003-10,

104. Pandolfi S, Montagnani V, Penachioni JY, Vinci MC, Olivito B, Borgognoni L, Stecca B. WIP1 phosphatase modulates the hedgehog signaling by enhancing GLI1 function. Oncogene. 2013;32:4737-47.

105. Yavari A, Nagaraj R, Owusu-Ansah E, Folick A, Ngo K, Hillman T, Call G, Rohatgi R, Scott MP, Banerjee U. Role of lipid metabolism in smoothened derepression in hedgehog signaling. Dev Cell. 2010;19:54-65.

106. Garcia-Gonzalo FR, Phua SC, Roberson EC, Garcia G 3rd, Abedin M, Schurmans S, Inoue T, Reiter JF. Phosphoinositides regulate ciliary protein trafficking to modulate hedgehog signaling. Dev Cell. 2015;34:400-9.

107. Jacoby M, Cox JJ, Gayral S, Hampshire DJ, Ayub M, Blockmans M, Pernot E, Kisseleva MV, Compere P, Schiffmann SN, et al. INPP5E mutations cause primary cilium signaling defects, ciliary instability and ciliopathies in human and mouse. Nat Genet. 2009;41:1027-31.

108. Bielas SL, Silhavy JL, Brancati F, Kisseleva MV, Al-Gazali L, Sztriha L, Bayoumi RA, Zaki MS, Abdel-Aleem A, Rosti RO, et al. Mutations in INPP5E, encoding inositol polyphosphate-5-phosphatase $E$, link phosphatidyl inositol signaling to the ciliopathies. Nat Genet. 2009;41:1032-6.

109. Mukhopadhyay S, Wen X, Ratti N, Loktev A, Rangell L, Scales SJ, Jackson PK. The ciliary G-protein-coupled receptor Gpr161 negatively regulates the sonic hedgehog pathway via CAMP signaling. Cell. 2013;152:210-23.

110. Patterson VL, Damrau C, Paudyal A, Reeve B, Grimes DT, Stewart ME, Williams DJ, Siggers P, Greenfield A, Murdoch JN. Mouse hitchhiker mutants have spina bifida, dorso-ventral patterning defects and polydactyly: identification of Tulp3 as a novel negative regulator of the sonic hedgehog pathway. Hum Mol Genet. 2009;18:1719-39.

111. Mukhopadhyay S, Wen X, Chih B, Nelson CD, Lane WS, Scales SJ, Jackson PK. TULP3 bridges the IFT-A complex and membrane phosphoinositides to promote trafficking of $\mathrm{G}$ protein-coupled receptors into primary cilia. Genes Dev. 2010;24:2180-93.

112. Norman RX, Ko HW, Huang V, Eun CM, Abler LL, Zhang Z, Sun X, Eggenschwiler JT. Tubby-like protein 3 (TULP3) regulates patterning in the mouse embryo through inhibition of hedgehog signaling. Hum Mol Genet. 2009:18:1740-54

113. Qin J, Lin Y, Norman RX, Ko HW, Eggenschwiler JT. Intraflagellar transport protein 122 antagonizes sonic hedgehog signaling and controls ciliary localization of pathway components. Proc Natl Acad Sci U S A. 2011;108:1456-61.

114. Bollen M, Peti W, Ragusa MJ, Beullens M. The extended PP1 toolkit: designed to create specificity. Trends Biochem Sci. 2010;35:450-8.

115. Hertz EP, Kruse T, Davey NE, Lopez-Mendez B, Sigurethsson JO, Montoya G, Olsen JV, Nilsson J. A conserved motif provides binding specificity to the PP2A-B56 phosphatase. Mol Cell. 2016;63:686-95.

116. Glatter T, Wepf A, Aebersold R, Gstaiger M. An integrated workflow for charting the human interaction proteome: insights into the PP2A system. Mol Syst Biol. 2009;5:237.

\section{Submit your next manuscript to BioMed Central and we will help you at every step:}

- We accept pre-submission inquiries

- Our selector tool helps you to find the most relevant journal

- We provide round the clock customer support

- Convenient online submission

- Thorough peer review

- Inclusion in PubMed and all major indexing services

- Maximum visibility for your research

Submit your manuscript at www.biomedcentral.com/submit
Biomed Central 